\title{
Note on Transcription and Transliteration
}

Madhu Nath's performance of the tales of Bharthari and Gopi Chand was transcribed by his nephew, Nathu Nath. Nathu had worked for the folklorist Joseph Miller before he worked for me. When not employed by foreign scholars he has made his living through agriculture, clerical jobs, tractor-driving, and temple service. Miller trained Nathu, along with several other young village men, to follow particular guidelines in his transcription work. These included: write every sound each time just as you hear it; don't standardize divergent pronunciations; don't Hindi-ize local dialect. Nathu was meticulous in his adherence to these, by and large excellent, standards. We thus escaped the syndrome, lamented by other folklore-collectors in India-where literate scribes revise as they transcribe, refusing to reproduce irregularities or language they consider unfit to be written down.

However, there are certainly occasional drawbacks to this method. Sometimes the same word, or especially name, is written in several different ways. Bharthari's father is a good example - he appears as Gandarap Syān, Gandaraph Sen, and Gandaraph Syān. I take the obvious decision to standardize this and other instances of phonetic fluidity.

I use a standard system to transliterate from Nathu's Devanagari to English. The question of when to use diacritics is a vexing one, for which there is no accepted standard. The conventions adopted here are as follows: I italicize and give diacritics for all Hindi and Rajasthani words that are not proper nouns whenever I use them, with the exception of those that have come into English-most 
notably "yogi." Proper nouns appear in plain roman type without diacritics. In appendix 2 I add an alphabetical list, subdivided by category, of important names with diacritics.

Some of the names and terms that appear in these pages belong to a wider Indian tradition and have a number of variant spellings. For the most part, I consistently employ name spellings that are in accord with Madhu Nath's speech, but in chapters 2 and 3 where I treat broader traditions, footnotes offer some of the better-known variants as they arise. I make a few concessions in cases when Madhu's variant is different from everyone else's; for example I use Bharthari where Madhu actually says Bhartari.

In organizing the translated text, I keep the bard Madhu Nath's own divisions and subdivisions. He thinks of, and performs, each epic in major, named parts. In the performance context, each part falls into segments - broken by Madhu's putting down his sārang $\bar{\imath}$, evoking the gods and gurus, coughing, and launching his prose explanation. The present text is numbered according to the title of the epic, the number of the part, the number of the segment, and whether it is singing or explanation. Thus GC I.5.e means the explanation of the fifth segment of the first part of Gopi Chand; Bh 2.I.s means the sung verses of the first segment of the second part of Bharthari.

In the interests of fluidity and space I omit most of the interjections from the designated respondant $(h \bar{u} \dot{n} k \bar{a} r)$, or other audience members, that characterize the performance of an explanation. These consist almost always of a monosyllabic "Yes" or "Ah!" or repetitions of a word the bard has just used. If, however, an audience comment does anything other than echo or affirm the content of the performance, it is included, set apart by slashes. A few descriptive notes are provided in brackets - for example: [Laughter]. Also bracketed are occasional verbal exchanges that are relevant, but not integral, to the performance.

I will be happy to make tapes or transcribed text available at the cost of duplication to any interested parties. In the case of Bharthari's tale, copies of the tapes are archived at the American Institute of Indian Studies' Centre for Ethnomusicology in New Delhi. 